\title{
Integration of Oral Health Into the Well- Child Visit at Federally Qualified Health Centers: Study of 6 Clinics, August 2014-March 2015
}

\author{
Judith Bernstein, MSN, PhD; Christina Gebel, MPH; Clemencia Vargas, DDS, PhD; \\ Paul Geltman, MD, MPH; Ashley Walter, MPH; Raul I. Garcia, DMD, MMSc; \\ Norman Tinanoff, DDS, MS
}

\begin{abstract}
Suggested citation for this article: Bernstein J, Gebel C, Vargas C, Geltman P, Walter A, Garcia RI, et al. Integration of Oral Health Into the Well-Child Visit at Federally Qualified Health Centers: Study of 6 Clinics, August 2014-March 2015. Prev Chronic Dis 2016;13:160066. DOI: http://dx.doi.org/10.5888/pcd13.160066.
\end{abstract}

\section{PEER REVIEWED}

\section{Abstract}

\section{Introduction}

Early childhood caries, the most common chronic childhood disease, affects primary dentition and can impair eating, sleeping, and school performance. The disease is most prevalent among vulnerable populations with limited access to pediatric dental services. These same children generally receive well-child care at federally qualified health centers. The objective of this study was to identify facilitators and barriers to the integration of oral health into pediatric primary care at health centers to improve problem recognition, delivery of preventive measures, and referral to a dentist.

\section{Methods}

We collected and analyzed background data and data from structured observations and 39 interviews with administrators and staff at 6 clinics in 2 states, Maryland and Massachusetts.

\section{Results}

Participants valued oral health across professional roles but cited limited time, lack of training and expertise, low caregiver literacy, and lack of shared medical and dental electronic records as barriers to cooperation. Facilitators included an upper-level administration with the vision to see the value of integration, designated team leaders, and champions. An administration's vision, not structural determinants, patient characteristics, or geographic location, predicted the level of integration. Interviewees generated multilevel recommendations to promote delivery of oral health preventive measures and services during a well-child visit.

\section{Conclusion}

Poor oral health contributes to health care disparities. Barriers to integrating dental care into pediatric medical practice at health centers must be overcome to improve oral health for children living in poverty, with a disability, at a rural address, or any combination of these. Implementation will require adapting delivery systems to support multidisciplinary collaboration. Strategies suggested here may point the way to enhancing children's oral health.

\section{Introduction}

Early childhood caries (ECC), the most common chronic childhood disease (1), affects the primary dentition of children under age 6; it also affects their sleep, nutrition, and school performance (1). ECC is on the US health care agenda (2) because of its high prevalence (3) and associated health disparities $(4,5)$, which are largely attributable to socioeconomic factors associated with race/ ethnicity, poverty, or both $(4,6)$. Approximately $77 \%$ of children on Medicaid have contacted a pediatric clinician within the past 6 months (7). Many of these children receive their care in federally qualified health care centers (FQHCs), which are already focused on prevention (8). The US Preventive Services Task Force recommends that all children receive fluoride varnish starting at the age of 6 months or first tooth eruption (9), but pediatric providers in FQHCs are often the only source of oral health education and preventive measures for vulnerable young people (10), according to multiple professional organizations (11-15). These organizations 
advocate an expanded role for pediatric primary care clinicians, including oral health counseling and referral by age 1 year to a dental home, defined by the American Academy of Preventive Dentistry as an ongoing relationship between a dentist and a patient (16). Having a dental home increases the likelihood of a subsequent dental visit (17).

A 2014 systematic review reported, however, that prevention of ECC has limited reach in community health settings (18), despite federal statutes requiring FQHCs to provide "primary health services" (Section 330), which includes "preventative dental services" in the definition of primary health services [42 U.S.C. $\S 254(\mathrm{a})(1)$ and $\$ 254 \mathrm{~b}$ (b)(1)(A)(i)(III)(hh)] (19). Recent studies confirm gaps in care and low screening and referral rates for children on Medicaid (20-22).

Unlike previous studies of challenges to oral health integration into pediatric well-child care (13), this study seeks specifically to understand gaps in oral health prevention services in FQHC pediatric care settings, with particular attention to barriers and facilitators, best practices, and recommendations elicited from staff.

\section{Methods}

We selected clinics at 3 diverse FQHCs in Massachusetts and 3 in Maryland to cover a range of geographic locations (rural, small community, and urban), organizational structures, patient populations, workforce composition, and financial resources across a continuum of oral health integration into pediatric services. Variables predictive of the level of integration of dental and pediatric services were determined from the literature on oral health integration into pediatric primary care. Clinics were ranked by their number of integration variables: 4 or 5 advanced integration, 3 intermediate, and 0 to 2 minimal. Contextual, organizational and professional data were collected from August 2014 through March 2015 in 3 formats: background information, key informant interviews, and direct observation. This project was classified exempt by institutional review boards at Boston University, the University of Maryland, and the University of Baltimore, where interview data were collected.

The chief financial officers (CFOs) or their designees provided information on a formatted spreadsheet on aggregate patient demographics, geographic and catchment area information, number and types of clinic personnel, operating budget and sources of income, description of oral health activities (if any), use of electronic medical records (EMR), and level of oral health integration into the pediatric EMR.
The study protocol specified 42 participants, 7 from each $\mathrm{FQHC}$, representing "decision makers, clinicians, and support personnel" (eg, FQHC clinic directors, medical directors, pediatric physicians, nurse practitioners, nurses, medical assistants, and dentists). Interviewers used a 45-60 minute semistructured interview via telephone to elicit relevance of oral health for general health, current practices, degree of integration and feasibility of oral health activities as part of pediatric primary care, recommendations for integration of oral health into pediatrics, perceived facilitators and barriers for integration, and potential strategies to remove barriers.

In both states, study investigators observed each site for 3-4hours. We used a tested oral health direct observation checklist (13) that included items on physical plant, workflow and patient throughputs, clinic surroundings, patient registration procedures, medical records charting issues, referrals and tracking, oral health discussions during medical appointments, distribution and storage of oral health preventive products, and degree of coordination of medical and dental clinics (if colocated).

For background information, we compared the formatted spreadsheets using Microsoft Excel. For key informant interviews, we transcribed audio recordings. Two qualitative data analysts and a senior member of the research team at Boston University independently coded 3 key informant interviews and assigned initial codes by using inductive coding methods, and then met to discuss the proposed code list to resolve any differences in interpretation. A master code list was entered into NVivo 10 software (QSR International). Interrater reliability was assessed and re-coded independently until interrater reliability was satisfactory $(\kappa$ coefficient greater than 0.70). The remaining interviews were coded, and new codes were discussed, defined, and added to the master list by the research team until the list reached saturation. Thematic analysis identified and enriched constructs specified in the literature and also allowed new ideas to emerge independently (23). For direct observations, these data were used to verify placement of the clinic on the continuum of integration and to verify clinical background.

\section{Results}

Correspondence between the proportion of patients with Medicaid insurance, the amount of uncompensated care, and the existence of collaborations with schools of dentistry were particularly notable (Table 1). Similarities in patient demographics and clinic characteristics (Table 2) existed across all levels of integration in these 6 FQHCs. Differences in size of population served and in clinic operating budgets were apparent, but we found no correlation between the level of integration of oral care into pediatric wellchild services (Table 1) and potential determinants such as clinic

\footnotetext{
The opinions expressed by authors contributing to this journal do not necessarily reflect the opinions of the U.S. Department of Health and Human Services, the Public Health Service, the Centers for Disease Control and Prevention, or the authors' affiliated institutions.
} 
size (defined as number of patients served), length of time in operation, rate of staff turnover, patient characteristics, geographic location, operating budget, or colocation of dental and pediatric practices (Table 1). For example, the most under-sourced clinic was the most highly integrated (Clinic A); the clinic with the highest rate of private insurance (Clinic C) was least likely to provide pediatric patients with dental referrals; and a clinic with a colocated dental practice had little integration, despite being in the same building (Clinic Z).

We present relevant comments from 39 completed interviews by theme to describe barriers and facilitators to integration of oral health care into well-child visits. Each comment was identified by the key informant's role and the level of integration in her or his work setting.

Perceptions of the importance of oral health were positive. Clinicians and administrators in all 6 clinics thought that oral health promotion for young children was crucial for a child to function normally and an important part of overall health care needs: "If you're in pain ... it's hard to focus, and sometimes it's hard to behave well. ... . Y ] ou can't function the way you want to" [pediatrician, advanced integration].

Clinicians and administrators noted the consequences for children of limited access to restorative dental care: "A lot of the families . . have a very simple screening at a school or [commercial dentistry] clinic. I think the parents . . . feel like they can check dental off the list ... but the kids have not had . . . comprehensive dental care" [chief executive officer (CEO), advanced integration].

Pediatric clinicians described significant challenges for parents, such as competing demands on time and energy, difficulties obtaining dental care, and low oral health literacy. "I think it's not important [to them] until it's a problem, and then it's very important" [pediatrician, advanced integration].

Clinicians described various barriers and gaps to including oral health in care delivery. In the clinical setting, time was a major challenge: "You've got a [patient] family. ... They're divorced, and the kids spend time in different places, and there's smokers in the house, and they don't eat right. They don't have a flush toilet, and they're playing hooky from school. After a while, how much can you fit into a 20-minute visit?" [chief medical officer (CMO), intermediate integration].

Administrators and clinicians spoke of concerns that oral health integration would overstep a pediatric clinician's defined role and expertise: "Where we're getting the challenge is not only the lack of [oral health] education ... . and sometimes the provider not being 'comfortable,' if you will, just because it's not their area of expertise and they're not trained a lot of times to look for certain things" [chief operating officer (COO), intermediate integration].

Both dental and pediatric clinicians felt going beyond a defined role could have potentially negative results for the patient by creating confusion or missing something: "Our exam is certainly not as thorough as the dental exam is going to be, and my biggest worry is the gum issues and the gum disease that we may not be picking up. ..." [CMO, intermediate integration]. "They [pediatricians] could do a cursory look, but a cursory look does not always tell you what's going on. So I always say, refer to the dental department" [dental director, advanced integration].

Many pediatric clinicians reflected on their lack of oral health training in pediatric residency programs or in the FQHC setting: "I don't think I've been to training at all. . . I think in med school, we did some mild stuff, but no additional training in any technique" [physician, minimal integration].

Clinicians and administrators in more integrated clinics reported efforts at collaboration between dental and pediatric units, with regular staff in-services, presentations, or meetings, but multiple clinic priorities limited the amount of time available for cross-specialty communication and education. "We do have some staff meetings ... like monthly. But, it seems like we're busy trying to put out a fire as opposed to coming out with newer ideas for moving forward" [dentist, advanced integration].

Across all clinics, we found that none of the clinic administrators or pediatric clinicians were aware of federal regulations requiring integration of oral health into pediatric practice in FQHCs (19), and they were also not familiar with the Bright Futures oral health guidelines, issued by the American Academy of Pediatrics (AAP) in conjunction with the Maternal and Child Health Bureau (24), or the Protecting All Children's Teeth (PACT) training program, which includes the AAP's guidelines for oral health best practices (15).

When facilitators to integration of oral health into pediatric well child care were discussed, several interviewees approved of a collaborative approach to health care delivery, and recognized the impact of oral health on other medical conditions: "I mean, you can't separate the mouth from the child and the dentist from the medical provider. It all needs to be integrated" [nurse practitioner, intermediate integration].

Staff in clinics with varying degrees of integration valued internal communication and working together on new or existing initiatives, and sharing resources to understand the context of a patient's

The opinions expressed by authors contributing to this journal do not necessarily reflect the opinions of the U.S. Department of Health and Human Services, the Public Health Service, the Centers for Disease Control and Prevention, or the authors' affiliated institutions. 
family life: "They may have a rapport with the family. They may know the family situation a lot better than me" [chief dental officer, intermediate integration].

Interviewees from some clinics also reported using outside resources, partnering with dental schools or outside private practices to increase access for their patients: "I've found that that is very helpful when the dental residents are here and they can be face-to-face with the patients. They come into all of our visits with us, and say, 'If you don't have a dentist, you can come see me upstairs" [pediatrician, advanced integration].

Furthermore, there was general agreement that integration could happen only with leadership and vision at the top. Upper-level administrators' involvement was seen as critical in setting the tone for clinic priorities and empowering clinical staff: "The administration has to buy in to the importance of pediatric oral health and has to make it a priority among all of the multiple priorities that we have" [senior VP of outreach, intermediate integration]

Several clinicians and administrators mentioned the importance of designating a team leader to promote oral health, and many also encouraged designating champions for oral health as team leaders: "Any transformation that happens within our practice, there is naturally one person that becomes the leader" [chief compliance officer, minimal integration].

In discussing system challenges, respondents noted numerous structural barriers to integrated health care delivery. EMR systems posed a significant barrier to integration in each of the clinics that were studied. At 4 of the 6 sites that were colocated, 2 different EMR programs were used for pediatrics and dental charting, with minimal communication between the 2 systems. Dental and medical providers reported tedious separate login procedures to gain access to patient records. Respondents, particularly at clinics with advanced integration, expressed a strong desire to have this crosscommunication, because both systems report on a patient's health. However, providers reported not knowing about the activities of their colleagues: "Well, I haven't seen what happens on the dental side because they are not here at my site" [nurse practitioner, intermediate integration]. "If the dentist was concerned about nutritional status ... we don't often get that information. While we are all connected under the health center, we are sort of together but we are separate" [pediatric nurse, minimal integration].

Another major challenge noted was the lack of an oral health template, a referral system for dental services, and the capacity to track referral outcomes: "I hope they make the appointment, and then they go to the clinic and that's where I lose it, unfortunately, in the loop" [nurse practitioner, intermediate integration]. "We're trying to figure out a better way to get feedback from the local dentists as well . . . but we haven't really formalized the process for that" [pediatrician, intermediate integration].

There were also challenges related to state and federal reimbursement policy. Concerns were raised by clinic administrators that some states have bundled (one fee) billing for a well-child visit: "There is no additional revenue unless they go into the dental chair .... We get the same amount of money from Medicaid on every child visit" [president chief executive, intermediate integration].

Interviewees were asked to reflect on what changes would be needed to integrate oral health into routine pediatric care. Their recommendations are listed in the Box.

\section{Box. Recommendations of Key Informants From 6 Federally Qualified Health Care Centers in \\ Massachusetts or Maryland, 2015}

Recommendation 1: Identify champions and foster leadership from the top of institutional hierarchies down to grass roots quality improvement committees.

Action Item 1.1: Widely disseminate evidence that supports inclusion of oral health promotion strategies in pediatric practice and relevant policy statements from professional organizations to federally qualified health center chief executive officers, chief medical officers, clinicians, and support staff.

Action Item 1.2: Review internal decision-making culture and structures to assess potential to be inclusive and conducive to change.

Action Item 1.3: Appoint 2 team leaders or oral health champions ( 1 from pediatrics and 1 from dentistry) who are in regular communication with upper-level management about progress and next steps for integration.

Action Item 1.4: Form an oral health committee, comprising many stakeholders involved in planning, implementation, and quality improvement.

Recommendation 2: Create an internal mechanism to reward health center staff champions, innovators, and oral health providers to develop and sustain integrated care within Centers; and establish external incentives for Centers that choose to implement integration of oral health into pediatrics within their health care systems.

Recommendation 3: Implement standardized, ongoing quality improvement measures.

\footnotetext{
The opinions expressed by authors contributing to this journal do not necessarily reflect the opinions of the U.S. Department of Health and Human Services, the Public Health Service, the Centers for Disease Control and Prevention, or the authors' affiliated institutions.
} 
Action Item 3.1: Evaluate documentation and ease of extraction of data about oral health procedures and prevention counseling, and remove barriers to data collection.

Action Item 3.2: Provide regular feedback to pediatric staff on oral health activities.

Recommendation 4: Provide greater opportunities for training pediatric staff in preventive oral health.

Action Item 4.1: Provide onsite workshops and links to useful oral health materials for all pediatric staff.

Recommendation 5: Increase funding for oral health in federally

qualified health centers and increase awareness of funding

opportunities.

Action Item 5.1: Increase funding opportunities to offer workshops on securing funding and using it to hire additional staff or expand dental-related activities, with a particular focus on connecting pediatric and dental efforts.

\section{Discussion}

The climate for integration in FQHCs was mixed. The participants valued oral health as a part of a child's overall health and well-being. They reported efforts toward dental and medical collaboration, as well as barriers that complicate or prevent these efforts. Interviewees nearly unanimously noted constrained time for well-child care, especially when caring for families with complex social needs. An FQHC could have colocation of dental and medical services, as did 4 of the 6 sites in this study, but results confirm other findings that colocation of services is only the initial step toward implementing interdisciplinary care (25). Interestingly, levels of oral health integration were not associated with the explanatory variables presented in Table 2 .

This study demonstrated that efforts toward interdisciplinary teambased collaboration can be complicated by professional boundaries, sometimes referred to as "professional silos" (26), as well as challenges from professional values, beliefs, attitudes, customs, and behaviors (27). Respondents felt uncomfortable stepping out of their defined roles and scope of practice, as noted in a recent report by the DentaQuest Foundation (13). This lack of confidence could be closely related to a nearly unanimous lack of training in medical or dental school, continuing education, or professional development. Providers need further education in assessment to improve accuracy in visible examinations in well-child care, and in anticipatory guidance, as demonstrated by a lack of knowledge of oral health guidelines, such as recommendations on age of first dental visit $(28,29)$. Interprofessional education improves core competencies (30) and could be a solution to overcoming this barrier.
As to systemic barriers, administrators and clinicians alike reported difficulty juggling multiple priorities and frustration with the lack of cross-communication in EMR systems. Finally, administrators and clinicians were unfamiliar with federal mandates and professional guidelines. Facilitators of integration were noted as well. Clinics with advanced integration, in particular, noted collaborative efforts between dental and pediatric staff. Clinic staff noted nearly unanimously that a committed vision from top administrators, designated team leaders, and oral health champions were necessary for meaningful change to occur. Key informants asked for ongoing quality improvement measures to highlight progress and identify gaps.

One surprising result from this study was that a clinic with low resources was among the most integrated in the study sample. The catchment area served by this clinic was recently named among the 3 poorest communities in its state, but the clinic's lack of resources was balanced by a strong commitment to cross-disciplinary collaboration on the part of its CMO and leadership and supervision of integrative programs at each level of function, from central administration to program implementation to quality assurance. Similarly, integration did not necessarily follow colocation, as shown in Clinic Z, where a large, vibrant dental practice with strong administrative leadership interacted well with Family Practice clinicians, but not nearly as well with pediatricians. Through site observation, we noted that the signs of integration in family practice far exceeded the signs of integration in pediatrics.

Certain recommendations made by interviewees (Box) are conducive to immediate or short-term action, even for clinics with limited resources. Leadership vision statements, naming of champions, formation of an oral health committee, and naming of oral health topics for quality assurance can be taken without extra financial resources. When these actions demand allocated time, support from upper-level administration would help to ease the demand on staff schedules. Dissemination of best practices for oral health integration can be coupled with other clinic- or communitywide efforts for health promotion. Addition of an oral health template to the pediatric EMR can be approached by existing informational technology support staff. Systems changes, such as compatibility between pediatric and dental EMR systems, will be more difficult to overcome and may require dedicated financial resources for technical support.

This study has some limitations. First, although this study included a range of clinics, a larger sample would be necessary to ensure generalizability. Second, key informants were identified by clinic administrators, who may have chosen staff known to be knowledgeable about oral health or especially motivated.

The opinions expressed by authors contributing to this journal do not necessarily reflect the opinions of the U.S. Department of Health and Human Services, the Public Health Service, the Centers for Disease Control and Prevention, or the authors' affiliated institutions. 
FQHCs provide services for the children with the highest prevalence of early childhood caries, and thus have the greatest opportunity to deliver effective prevention measures. This study shows that pediatric administrators and clinicians in FQHCs collectively have the will but not yet the means to improve oral health and overall health for the children, families, and communities they serve. The strategies they suggested to remove barriers and challenges deserve further investigation and support.

\section{Acknowledgments}

The authors have no relevant financial relationships and no conflicts of interest apply. This study was supported by cooperative agreement U54 DE019275 from the National Institute of Dental and Craniofacial Research.

\section{Author Information}

Corresponding Author: Judith Bernstein, MSN, PhD, Professor, Dept of Community Health Sciences, Boston University, 801 Massachusetts Ave 431B, Boston, MA 02118. Telephone: 617414-1415. Email: jbernste@bu.edu.

Author Affiliations: Christina Gebel, Paul Geltman, Ashley Walter, Raul Garcia, Boston University, Boston, Massachusetts; Clemencia Vargas, Norman Tinanoff, Boston University and University of Maryland School of Dentistry, Baltimore, Maryland.

\section{References}

1. Department of Health and Human Services, U.S. Public Health Service. Oral health in America: a report of the Surgeon General. National Institute of Dental and Craniofacial Research, National Institutes of Health; 2000. http:// profiles.nlm.nih.gov/ps/retrieve/ResourceMetadata/NNBBJT/. Accessed March 11, 2016.

2. Office of Disease Prevention and Health Promotion. Oral health | healthy people 2020; 2015. http:// www.healthypeople.gov/2020/topics-objectives/topic/oralhealth/objectives?topicId=32. AccessedMarch 11, 2016.

3. Dye B, Thornton-Evans G, Li X, Iafolla T. Dental caries and sealant prevalence in children and adolescents in the United States, 2011-2012. CDC National Center for Health Statistics; 2015. http://www.cdc.gov/nchs/data/databriefs/db191.pdf. AccessedMarch 11, 2016.

4. Institute of Medicine. Advancing oral health in America. 2011. http://books.nap.edu/openbook.php?record_id $=13086$. AccessedMarch 11, 2016.
5. Bloom B, Jones LI, Freeman G. Summary health statistics for U.S. children: National Health Interview Survey, 2012. Vital Health Stat 10 2013;(258):1-81.

6. Fisher-Owens SA, Gansky SA, Platt LJ, Weintraub JA, Soobader M-J, Bramlett MD, et al. Influences on children's oral health: a conceptual model. Pediatrics 2007; 120(3):e510-20.

7. Summary health statistics tables for U.S. children: National Health Interview Survey, 2014, table C-8. http://www.cdc.gov/ nchs/fastats/physician-visits.htm. Accessed March 2, 2016.

8. Jones E, Shi L, Hayashi AS, Sharma R, Daly C, Ngo-Metzger Q. Access to oral health care: the role of federally qualified health centers in addressing disparities and expanding access. Am J Public Health 2013;103(3):488-93.

9. United States Preventive Services Task Force. USPSTF Recommendations $A$ and $B$ by date. http:// www.uspreventiveservicestaskforce.org/Page/Name/uspstf-aand-b-recommendations-by-date/. Accessed March 2, 2016.

10. Health Resources and Services Administration. Integration of oral health and primary care practices. Rockville (MD): US Department of Health and Human Services; 2014.

11. American Academy of Pediatric Dentistry. Policy on early childhood caries (ECC): classifications, consequences, and preventive strategies. American Academy of Pediatric Dentistry; 2015. Report No.: v 37 no. 6. http://www.aapd.org/ media/Policies_Guidelines/P_ECCClassifications.pdf. AccessedMarch 11, 2016.

12. The American Academy of Periodontics, National Network for Oral Health Access. Oral health and the patient-centered health home. 2012. http://www.aachc.org/wp-content/uploads/2014/ 01/OralHealthPCHH.pdf. Accessed March 22, 2016.

13. AAPD The Pediatric Oral Health Research and Policy Center. Mitchell-Royston L, Nowak A, Silverman J. Interprofessional study of oral health in primary care. Dentaquest Foundation; 2014 . ht tp://www.aapd.org/as sets/1/7/ Dentaquest_Year_1_Final_Report.pdf. AccessedMarch 11, 2016.

14. National Maternal and Child Health Oral Health Resource Center. Focus on the dental home - OHRC. http:// www.mchoralhealth.org/highlights/dentalhome.php. AccessedMarch 11, 2016.

15. Protecting all children's teeth. https://www2.aap.org/ oralhealth/pact/index-cme.cfm. AccessedMarch 11, 2016.

16. Section on oral health. Maintaining and improving the oral health of young children. Pediatrics 2014;134(6):1224-9.

17. Beil HA, Rozier RG. Primary health care providers' advice for a dental checkup and dental use in children. Pediatrics 2010; 126(2):e435-41.

\footnotetext{
The opinions expressed by authors contributing to this journal do not necessarily reflect the opinions of the U.S. Department of Health and Human Services, the Public Health Service, the Centers for Disease Control and Prevention, or the authors' affiliated institutions.
} 
18. Chou R, Cantor A, Zakher B, Mitchell JP, Pappas M. Prevention of dental caries in children younger than 5 years old: systematic review to update the U.S. Preventive Services Task Force Recommendation. Agency for Healthcare Research and Quality (US); 2014. http://www.ncbi.nlm.nih.gov/books/ NBK202090/. AccessedMarch 11, 2016.

19. Children's Dental Health Project. Increasing access to dental care through public private partnerships: contracting between private dentists and federally qualified healthcare centers. Washington (DC): Children's Dental Health Project; 2011. https://www.cdhp.org/resources/243-fqhc-handbookincreasing-access-to-dental-care-through-public-privatepartnerships. Accessed March 11, 2016.

20. Mann C. Update on CMS oral health initiative and other oral health related items. Baltimore (MD): Center for Medicaid and CHIP Services; 2014. http://www.medicaid.gov/FederalPolicy-Guidance/downloads/CIB-07-10-2014.pdf. AccessedMarch 11, 2016.

21. Jones E, Shi L, Hayashi AS, Sharma R, Daly C, Ngo-Metzger Q. Access to oral health care: the role of federally qualified health centers in addressing disparities and expanding access. Am J Public Health 2013;103(3):488-93.

22. Close K, Rozier RG, Zeldin LP, Gilbert AR. Barriers to the adoption and implementation of preventive dental services in primary medical care. Pediatrics 2010;125(3):509-17.

23. Harvard University. Thematic analysis: foundations of qualitative research in education. Foundations of qualitative research in education. 2015. http://isites.harvard.edu/icb/ icb.do?keyword=qualitative \&pageid=icb.page 340897 . AccessedMarch 11, 2016.

24. Bright Futures. Promoting oral health. 2013. https:// brightfutures.aap.org/Bright $\% 20$ Futures\%20Documents/8Promoting_Oral_Health.pdf. Accessed March 2, 2016.

25. Formicola AJ, Ro M, Marshall S, Derksen D, Powell W, Hartsock L, et al. Strengthening the oral health safety net: delivery models that improve access to oral health care for uninsured and underserved populations. Am J Public Health 2008;98(9,Suppl 1):S86-8.

26. Vanderbilt AA, Dail MD, Jaberi P. Reducing health disparities in underserved communities via interprofessional collaboration across health care professions. J Multidiscip Healthc 2015; 8:205-8.

27. Hall P. Interprofessional teamwork: professional cultures as barriers. J Interprof Care 2005;19(Suppl 1):188-96.

28. Dumas SA, Weaver KE, Park SY, Polk DE, Weyant RJ, Bogen DL. Accuracy of visible plaque identification by pediatric clinicians during well-child care. Clin Pediatr (Phila) 2013; 52(7):645-51.
29. Bernstein HH, Dhepyasuwan N, Connors K, Volkan K, Serwint JR;CORNET Investigators. Evaluation of a national Bright Futures oral health curriculum for pediatric residents. Acad Pediatr 2013;13(2):133-9.

30. Hallas D, Fernandez JB, Herman NG, Moursi A. Identification of pediatric oral health core competencies through interprofessional education and practice. Nurs Res Pract 2015; 2015:360523.

\footnotetext{
The opinions expressed by authors contributing to this journal do not necessarily reflect the opinions of the U.S. Department of Health and Human Services, the Public Health Service, the Centers for Disease Control and Prevention, or the authors' affiliated institutions.
} 


\section{Tables}

Table 1. Levels of Integration of Oral Health Prevention and Services Into Pediatric Well-Child Care at 6 Federally Qualified Health Care Centers in Massachusetts or Maryland, 2015

\begin{tabular}{|c|c|c|c|c|c|c|}
\hline \multirow[b]{2}{*}{ Characteristic } & \multicolumn{2}{|c|}{ Advanced Integration } & \multicolumn{2}{|c|}{ Intermediate Integration } & \multicolumn{2}{|c|}{ Minimal Integration } \\
\hline & Clinic A & Clinic X & Clinic B & Clinic Y & Clinic C & Clinic Z \\
\hline \multicolumn{7}{|l|}{ Electronic medical record integration } \\
\hline Oral health template or flag in pediatric EMR & No & No & No & No & No & No \\
\hline Access to pediatric and dental problem lists & Yes & No & No & No & No & No \\
\hline Automated referral tracking & No & No & No & No & No & No \\
\hline \multicolumn{7}{|l|}{ Clinical practices } \\
\hline $\begin{array}{l}\text { Formalized referrals for oral health (does not include self- } \\
\text { referral) }\end{array}$ & Yes & Yes & Yes & No & No & Yes \\
\hline Fluoride varnish application in pediatrics & No & Yes & No & Yes & No & No \\
\hline Caries risk assessments (beyond visual inspection) & No & No & No & No & No & No \\
\hline \multicolumn{7}{|l|}{ Staff characteristics } \\
\hline Includes an oral health champion & Yes & Yes & Yes & Yes & Yes & No \\
\hline Regular dental/pediatric training or meetings & No & Yes & No & No & No & No \\
\hline \multicolumn{7}{|l|}{ Clinic characteristics } \\
\hline Certified medical home & Yes & Yes & Yes & Yes & Yes & Yes \\
\hline Colocation with dental clinic & Yes & Yes & Yes & No & No & Yes \\
\hline \multicolumn{7}{|l|}{ Partnerships } \\
\hline Networking with local dental practices if not colocated & NA & NA & NA & Yes & Yes & NA \\
\hline Formal dental school partnerships & Yes & Yes & Yes & No & No & Yes \\
\hline Total number of integration variables & 4 & 5 & 3 & 3 & 2 & 2 \\
\hline
\end{tabular}

Abbreviation: NA, not applicable. 
Table 2. Patient Demographics and Structural Characteristics by Level of Integration of 6 Federally Qualified Health Care Centers in Massachusetts or Maryland, 2015

\begin{tabular}{|c|c|c|c|c|c|c|}
\hline \multirow[b]{2}{*}{ Characteristics } & \multicolumn{2}{|c|}{ Advanced Integration } & \multicolumn{2}{|c|}{ Intermediate Integration } & \multicolumn{2}{|c|}{ Minimal Integration } \\
\hline & Clinic A & Clinic X & Clinic B & Clinic Y & Clinic C & Clinic Z \\
\hline \multicolumn{7}{|c|}{ Pediatric clinic patients } \\
\hline No. of patients & 7,462 & 6,515 & 10,480 & 9,824 & 534 & 11,460 \\
\hline \multicolumn{7}{|l|}{ Age of patients } \\
\hline $0-5 y$ & 3,077 & 1,460 & 2,532 & 3,208 & 94 & 3,005 \\
\hline $6-13 y$ & 2,374 & 2,589 & 4,783 & 3,256 & 175 & 3,874 \\
\hline $14-21 y$ & 2,011 & 2,466 & 3,165 & 3,360 & 265 & 4,581 \\
\hline \multicolumn{7}{|l|}{ Race/ethnicity, \% } \\
\hline Non-Hispanic white & 4.0 & 10.3 & 87.0 & 28.0 & 100 & 18.3 \\
\hline Non-Hispanic black & 88.0 & 2.0 & 4.9 & 10.0 & 0 & 10.7 \\
\hline Hispanic & 3.5 & 79.5 & 8.1 & 30.0 & 0 & 48.9 \\
\hline Asian & 0.8 & 1.9 & 0 & 27.0 & 0 & 6.2 \\
\hline Other & 3.7 & 6.3 & 0 & 5.0 & 0 & 15.9 \\
\hline Limited English proficiency, \% & 4.0 & 32.0 & 70.0 & 45.0 & 0 & 55.8 \\
\hline \multicolumn{7}{|l|}{ Payer source, \% } \\
\hline Private & 9.0 & 3.1 & 6.0 & 16.0 & 30.0 & 11.0 \\
\hline Medicaid & 87.0 & 96.1 & 75.0 & 82.0 & 50.0 & 85.0 \\
\hline CSHCN & 0 & 0.6 & 9.0 & 0 & 0 & 0 \\
\hline Self-pay & 4.0 & 0 & 10.0 & 2.0 & 20.0 & 4.0 \\
\hline \multicolumn{7}{|c|}{ Clinics } \\
\hline Geographic location & Urban & Small City & Rural & Urban & Rural & Urban \\
\hline Patient population size (catchment area), $\mathrm{n}$ & 208,979 & 40,249 & 90,000 & 200,000 & 100,000 & 90,000 \\
\hline Years in operation, $\mathrm{n}$ & 42 & 40 & 30 & 40 & 8 & 40 \\
\hline Operating budget, $\$$, in millions & 11.4 & 35.4 & 14.3 & 34.5 & 2.9 & 66.0 \\
\hline Uncompensated care, \% & 13.6 & 0 & $10-15$ & 9 & 7 & 12.0 \\
\hline Years $\mathrm{CMO}$ in office & 8 & 0.5 & 2 & 15 & $<1$ & 4 \\
\hline Clinical staff turnover & Low & Low & High & High & High & Low \\
\hline
\end{tabular}

Abbreviations: CSHCN, children with special health care needs; $\mathrm{CMO}$, chief medical officer.

The opinions expressed by authors contributing to this journal do not necessarily reflect the opinions of the U.S. Department of Health and Human Services, the Public Health Service, the Centers for Disease Control and Prevention, or the authors' affiliated institutions. 